\title{
The Exercise of Moral Imagination in Stigmatized Work Groups
}

Esther Roca

\begin{abstract}
This study introduces the concept of moral imagination in a work context to provide an ethical approach to the controversial relationships between dirty work and dirty workers. Moral imagination is assessed as an essential faculty to overcome the stigma associated with dirty work and facilitate the daily work lives of workers. The exercise of moral imagination helps dirty workers to face the moral conflicts inherent in their tasks and to build a personal stance toward their occupation. Finally, we argue that organizations with dirty work groups should actively adopt measures to encourage their employees' exercise of moral imagination. This study investigates how organizations might create conditions that inspire moral imagination, particularly with regard to the importance of organizational culture as a means to enhance workers' moral sensitivity. Furthermore, this investigation analyzes different company practices that may derive from a culture committed to moral imagination.
\end{abstract}

KEY WORDS: moral imagination, dirty work, moral conflicts, stigma, work groups

\section{Introduction}

I think some [parents] are disappointed when you say you're going into psychiatric nursing. (cited in Wells et al., 2000, p. 84)

Negative and stigmatizing assessments regarding mental health nursing discredit the valuable contri butions of mental health nurses; but more impor tantly, these beliefs discount the needs of people who require access to mental health care. Oermann and Sperling (1999) observe that, unfortunately, recruitment of psychiatric practitioners is not keep ing pace with the growing need among the mentally ill, perhaps because of its negative societal rejection. In general, society censures certain occupations or the methods employed in their exercise; moral controversy generated by such jobs triggers a stigma for their practitioners. These controversial occupa tions, including mental health jobs, provoke ques tions about their legitimacy and aggressive reactions from some members of society. For various reasons, seemingly very different professions, such as grave diggers or exotic dancers, require their practitioners to defend their career choices.

Hughes (1951) refers to these very diverse and stigmatized occupations as "dirty work," a term he defines as occupations likely to be perceived as dis gusting or degrading by wider society. The definition includes all tasks that seem physically, psychologically, or morally tainted, because society views the specific characteristics of those jobs, as well as the contro versies that often surround them, as reasons to devalue such occupations. The resulting social rejection may affect the self perception of people who work in these jobs.

Social science research on stigmatization has grown significantly in the past three decades, par ticularly in social psychology realms. The roles that people play at work and the groups and organiza tions with which they affiliate offer potentially powerful sources of stigmatization, according to social psychologists, sociologists, and organizational theorists (Goffman, 1963; Link and Phelan, 2001; Paetzold et al., 2008). Much research relies on eth nographic and organizational identity findings that indicate that dirty workers are acutely aware of the stigma associated with their occupations (Bolton, 2005; Tracy, 2004). In turn, they have studied the ambivalent stance toward their work that many dirty workers adopt, and propose diverse solutions to transform its meaning and mitigate the impact of the pervasive stigmas on their identity (Ashforth and Kreiner, 1999). In general, these workers seek to build a personal response and stance toward their 
jobs that will enable them to protect their identity not an easy task in some cases.

Scholars also note the harmful effects of stigma tization on organizations and their members, as well as on society in general. Stigmatized work groups suffer discrimination and social refusal, which harms workers' identity, self perception, and subsequent work performance. As prior studies show, the effects also emerge as organizational dysfunctions, such as high employee turnover and poor performance. In addition, these conflicts might affect general social welfare, because many dirty jobs are essential, such as psychiatric nurses and hospital cleaning staff (Dutton et al., 1996). Paradoxically, society seems to stig matize occupations that it needs urgently and even sometimes recognizes as heroic [e.g., social services counseling, acquired immune deficiency syndrome (AIDS) advocates]. "Dirty" work groups may even be marginalized by "clean" work groups in the same company, which generates internal conflicts that will clearly harm performance.

In this investigation, we defend the exercise of moral imagination as crucial for a dual task by which dirty workers construct a personal stance toward their jobs and also confront the moral dilemmas inherent in their daily work. Thus, we propose moral imagination as a means to understand the moral conflicts that emerge for stigmatized occupa tions, as well as consider how it might help workers face these conflicts.

Specifically, this article attempts to answer the following questions: Why do dirty workers need enhanced moral imagination? Can moral imagina tion help dirty workers face morally ambiguous sit uations? What role might moral imagination play in overcoming the stigma associated with dirty occu pations? Finally, should organizations with stigma tized work groups actively work to encourage their employees' moral imagination? By answering these questions, this research contributes to several streams of business ethics and organizational literature.

In particular, the concept of moral imagination traditionally appears in the field of business ethics to describe ethical decision making processes (Hartman et al., 2006; Moberg and Seabright, 2000; Seabright and Schminke, 2002; Werhane, 1999). We instead use this concept for a more specific, unique purpose. Moral imagination in prior research is applied in a business context and relates to other organizational issues, such as organizational culture (Caldwell and Moberg, 2006); however, no prior study assesses its role to facilitate dirty workers' daily work and over come the stigma they face. We show that moral imagination can play this crucial role by facilitating coherent decision making processes, as well as sug gesting creative solutions to situations that are morally ambiguous according to our values. Because moral imagination supports moral decision making, it also might help socially dirty workers to face the constant moral conflicts that emerge during their daily work. Thus, we conclude that companies with dirty work groups should adopt measures to promote their employees' exercise of moral imagination.

The peculiar nature and stigma of dirty work, as well as the need to reconsider some aspects of managing these occupations, also represent frequent subjects in ethnographic and organizational identity literature (Ashforth and Kreiner, 1999; Ashforth et al., 2007; Dick, 2005). These studies analyze dirty work as a social construction and offer ideological techniques and social practices that might enable workers to achieve social affirmation. Without neglecting the important contributions of these studies, we move our analysis toward an ethical perspective. That is, by applying moral imagination to stigmatized occupations, we introduce an ethical dimension to a problem that traditionally has been treated as a psychological or social issue, especially in organizational identity literature. We attempt to show that stigmas attached to dirty work may be engendered by others' ethical views, so overcoming them will require an ethical attitude, as provided by moral imagination. The development of dirty workers' moral imagination may be a prerequisite for implementing techniques proposed by organi zational identity scholars; it also adds a personal dimension to their application.

The remainder of this article is organized as fol lows. First, we introduce three relevant roles played by moral imagination in moral decision making in the workplace. We consistently refer to these moral imagination facets throughout this article to analyze dirty occupations. Second, we explain the conflicts and controversies that such occupations generate, as well as our focus on socially dirty work, rather than physically or morally dirty work. Third, we explain the role that moral imagination can play in dirty workers' moral dilemmas. Fourth, we explain how 
social subgroups emerge to support the stigmatized worker in dealing with externally unfavorable assessments and complex decisions. Fifth and finally, we reflect on some organizational implications and discuss different organizational practices that may promote the exercise of members' moral imagination.

\section{Moral imagination in the workplace}

More than a decade has passed since Werhane (1998) introduced the concept of moral imagination to the field of business ethics. Collier (2006, p. 312) explains that the presence of imagination in moral judgments "is associated with the move to pragmatism in epis temology and with the shift to classical Aristotelian ism in ethics." This concept, derived from philosophy (Nussbaum, 1990; Tivnan, 1995), has been subject to varied treatments by organizational scholars, especially in the field of business ethics (e.g., Caldwell and Moberg, 2006; Collier, 2006; Hartman et al. 2006; Moberg and Seabright, 2000; Seabright and Schminke, 2002; Werhane, 1999), in an effort to acquire better understanding of the moral decision making process. Unfortunately, moral imagination lacks a common and succinct definition (Jacobs, 1991; Johnson, 1993). The most common concep tualization categorizes it as a faculty that plays an important role in moral decision making by helping people to grasp the moral quality of a situation and facilitating linked decisions. In general, moral imag ination emerges as an overriding sense that enables people to recognize the context and personal cir cumstances of their decisions, create images of the future to illuminate the present, and develop critical self reflections about their potential as moral crea tures. Intuitively, it appears to refer to the emotional and critical components of moral deliberation and also has been related to the concept of practical wisdom (Roca, 2007).

In line with Werhane, Caldwell and Moberg (2006) note three relevant roles played by moral imagination in moral decision making in the work place. This perspective is coherent with Rest's model of ethical decision making as employed by Moberg and Seabright (2000) to clarify the significance of moral imagination. Later, we analyze how these concrete aspects of moral imagination may be par ticularly relevant for our analysis of dirty occupations.

\section{Moral intuition}

Moral imagination initiates imaginative moral intu ition that recognizes the moral content of a given situation, even if it is not easily evident, and crea tively envisions its potential repercussions. In moral situations, imagination expands and evokes more facets, which generate additional possible actions and scenarios. Moral imagination also contributes to the elaboration of a wider moral awareness of a situation or dilemma, which helps the worker create potential courses of personal action.

This moral intuition generally appears as a double awareness. First, it provides a broader perception of the underlying ethical issues and repercussions of any action or attitude adopted toward a conflict laden situation. Second, it implies a more complete per ception of diverse perspectives that includes the person's own and others' feelings and values. In the empathetic process of perspective taking, that is, taking the perspective of others involved in the decision context (Piaget, 1932), moral imagination activates a deep sensitivity about the person's own feelings and prospects, as well as those of others. On the one hand, the process by which others' perspec tive becomes one's own should make the person more empathic toward stigmatized groups (Sheehan et al., 1989). On the other hand, and as we discuss in the next section, wider perception and awareness of one's own feelings and virtues seem crucial to make decisions that are coherent with personal values. The empathic facet of moral imagination thus makes a person more open minded, which may mean more critical but also more tolerant. Both properties are essential for consolidating a positive relationship between the self and the dirty job, as well as to understand the challenges that dirty work groups face.

\section{Moral judgment, principles, and values}

Moral imagination helps moral reasoning, which enables moral judgments, but it is important to differentiate these elements. Moral imagination is not the same as moral reasoning; rather, it acts on moral deliberation as its emotional facet. As Werh ane (1999) explains, "moral imagination is an affective facilitating process that influences, but is not identical, to moral reasoning." Rational and 
emotional elements join together in moral deliber ation, and moral imagination illuminates them to create a more complete, critical, and personal sce nario. Various research fields investigate the promi nence of and roles played by both emotional and rational elements in moral deliberation; for example, in philosophy and sociology, scholars study the rational and emotional weight of practical wisdom, which derives from the consideration of human beings as creatures of reason and feeling (see the special issue of Social Epistemology; McKenna et al., 2007). They assert that the exercise of practical wisdom can articulate knowledge by integrating values and emotions. Other scholars, using Blasi's (1980) and Kohlberg's (1969) work, emphasize the rational factors and argue that intelligence is a causal factor of good moral reasoning and behavior. Still other scholars develop diverse views of how imagi nation and the emotional facet of practical wisdom might influence moral decision making (Alexander, 1993; Fesmier, 1999; Johnson, 1993; Kekes, 1991; Larmore, 1981; McCullough, 1991; Roca, 2008; Tivnan, 1995; Werhane, 1999; Williams, 1997).

In general, we assert that moral imagination acti vates both affective and rational responses during ethical reflections and contributes to moral delibera tion by providing more critical and coherent decision processes in two aspects. First, during moral judg ment, moral imagination provides the critical ability and flexibility to use moral criteria, and the intuition needed for moral judgment. Second, it reminds the person of his or her own moral values and principles and thus activates diverse moral selves (Markus and Nurius, 1986) and images of the self who we want to be as a moral person (Schwalbe, 1991). Moral imag ination helps people disclose their own moral values and make coherent decisions. This aspect is crucial with regard to the dilemmas faced by dirty workers. In general, more complete awareness should favor the generation of different actions and the adoption of a stance consistent with the person's moral values. Therefore, moral imagination helps people make decisions that align with their own moral identity.

\section{Critical creativity}

Finally, the creative facet of moral imagination pushes moral evaluation into a rich reevaluation, beyond traditional deliberation and scenarios. The imaginative and critical exploration of possibilities and consequences enhances disengagement from the self and the immediate context to envision more innovative ones. As we explain subsequently, this ability should be crucial to dirty workers in their efforts to disengage from the "dirt" and explore unconventional approaches, as are often required by their unconventional jobs. These workers are also consistently exposed to complex moral conflicts regarding the appropriate means to employ. Moral imagination can offer richer and innovative ways to face these unconventional and complex dilemmas.

\section{Dirty work-dirty worker relationships}

As we mentioned previously, the concept of dirty work was originally invoked by Everett Hughes to refer to occupational activities likely to be perceived as physically, socially, or morally disgusting or degrading. This definition embraces an extensive variety of tasks and any occupation that seems in some way tainted. Following Hughes's (1951) con ceptualization, we consider a refuse collector, a psychiatric nurse, and a pawnbroker as exemplars of diverse types of these dirty occupations.

Ashforth and Kreiner (1999) also analyze various conflicts that these tasks generate for their subjects and explain how workers might respond to the taint of their jobs. Many dirty workers adopt an ambiv alent stance toward their jobs; they also face diffi culties in attempting to build a positive sense of identity, because their sense of self tends to be grounded in their roles and relies on others' positive affirmation (Albert et al., 2000; Ashforth, 2001; Pratt, 1998). In general, organizational identity re search observes that societal rejection directly affects the sense of self in the workplace and demands sociological-psychological solutions.

Workers' low self esteem, due to their occupa tions, likely becomes manifest at different levels. From an organizational perspective, workers' low consideration of their own work may induce high turnover or low productivity. At a more global level, it results in a paradox. In some cases, the same workers who provoke repugnance in society are those most urgently needed to enable society to survive. As we consider subsequently, most dirty 
jobs are desperately required from a social point of view, such as janitors, gravediggers, or police officers (Hughes, 1962), though not all of them are. How ever, people still avoid contact with these groups, even those whose work they applaud; the stigmati zation results precisely from the distance they attempt to maintain. However, in several cases the stigma may be due to ethically substantial conflicts, so overcoming it demands an ethical response, as provided by moral imagination.

At this point of our analysis, we distinguish the three types of dirty work invoked by Hughes (1951) and identify those that are more significant for our study, that is, those for which workers' moral imagination might play a more relevant role.

\section{Physical, social, and moral taint}

Consistent with Hughes's (1951) definition, Ashforth and Kreiner (1999) establish that, in a physically dirty occupation, workers deal directly with some disgusting material (e.g., janitors, exterminators, gravediggers); in contrast, "an occupation is socially tainted when [it] involves regular contact with peo ple or groups that are themselves regarded as stig matized" (e.g., AIDS worker, psychiatric assistant, police officer) (Dick, 2005). Finally, occupations are tainted morally if they are regarded as somewhat sinful or of dubious virtue (e.g., pawnbroker, casino croupier, stripper). Dirty work also may be tainted on several dimensions, such as a gravedigger, who seems tainted on both the social and the physical dimen sions, though one of these dimensions likely has greater weight in defining the occupation as dirty. Furthermore, the differences associated with these tainted occupations not only are taxonomical but also demand different treatments.

Previous work often considers the influence of occupational prestige on such tasks. In this sense, prestige may mitigate or enhance the taint associated with some occupations (Treiman, 1977). This effect is especially strong for occupations that are not affected by moral controversies. Compare, for example, the social perception of a physically dirty profession, such as a dentist or surgeon, with that of a janitor. However, the prestige effect appears less significant for socially or morally dirty occupations, such that people's perceptions of a tattoo designer and the owner of the tattoo shop are likely sub stantially the same. Prestige also cannot mitigate the taint of working for a tobacco company, regardless of the person's position in the company. The effect may even be opposite, such that the chief executive officer (CEO) of a tobacco company, who gains riches by endangering others' health, might be per ceived even more negatively than a blue collar worker employed by the same company. In general, we can assert that socially and morally dirty occu pations are less affected by occupational prestige than are physically dirty ones.

Because moral imagination is a helpful mechanism for dealing with morally ambiguous decision making processes, we posit that its impact on phys ically dirty work lacks significance. Paradoxically, its application to morally dirty work also results in lessened appeal. Therefore, our analysis focuses on a narrower scope, namely socially dirty work.

Both morally and socially dirty work are tainted by moral controversies, but two important aspects dif ferentiate them: (a) the type of moral controversy that affects them and (b) their social relevance. In morally dirty work, the controversy affects the occupation per se. Even if these morally debatable dirty jobs operate legally (e.g., prostitution in Denmark), they are inherently affected by a moral conflict that leads some members of society to question whether they should exist or argue that they are immoral and have negative effects on the community. The lack of common legislation and clashes with diverse com munity groups reflect this intrinsic moral controversy and ambiguity. The debate is not about the means employed for its performance but rather about the essence of the work. At the very least, it is question able whether this work contributes to human dignity and community welfare.

Socially dirty work is radically different. Nobody questions the moral content of an occupation such as an AIDS worker or police officer; their social necessity and positive effects on the community justify them absolutely. Nevertheless, these tasks and their subjects can experience both moral contro versies and stigmas, due to the means employed, such as the use of drugs to assist psychiatric patients. In these cases, workers' moral imagination should be especially relevant, because it influences decision making processes and could help socially dirty workers face the constant moral conflicts usually 
referred to the means by which they conduct their daily work. We explain this reasoning in the next section. Overall though, the distinction among the three types of dirty work leads us to limit our analysis to socially dirty work and exclude physically and morally dirty work.

\section{Managing dirtiness with moral imagination}

The potential positive effects of moral imagination exercise on dirty work do not appear in prior business ethics or organizational literature. Traditionally, dirty work and the stigma associated with it have been treated as psychological or social issues (Aviram and Rosenfeld, 2002; Goffman, 1963). We instead introduce a moral dimension to a problem that might have ethical roots. That is, stigmas may be due to ethically substantial reasons, such that overcoming them could involve an ethical attitude, as provided by moral imagination. The application of moral imagi nation to stigmatized occupations implies positioning the problem as an ethical issue and thus demands ethical solutions.

An established personal and ethical attitude be comes imperative to face moral dilemmas, because it facilitates decision processes and consequently can mitigate stigmas. We explore how moral imagina tion might contribute to establish a personal ethical attitude crucial for dirty workers.

\section{What dirtiness?}

However, why might the exercise of moral imagi nation help dirty workers? Dirty workers consistently face two types of moral conflicts in their work lives: the constant moral dilemmas that emerge during the course of their daily work, and initial conflict that stigmatizes the occupation itself. Because moral imagination supports complex moral decision making processes, it might help socially dirty workers make decisions that enable them to face moral con flicts consistently.

Most dirty work entails repeated moral dilemmas and issues, especially with regard to the methods used to accomplish the work. Such conflicts (e.g., use of drugs, coercive force) repeatedly put the worker in a difficult situation that demands a con troversial decision. These conflict laden situations may result from the stigmatized group with which the dirty workers interact (e.g., mental illness suf ferers, criminals). Furthermore, societal rejection can be provoked by these groups and the controversies associated with ways to manage them.

The stigma is thus associated with a moral con troversy that makes certain occupations repulsive to society and prompts people to seek distance from them. The typology of these jobs forces workers to confront situations infused with moral content but that demand concrete decisions; therefore, the workers need to adopt a personal stance toward these decisions. Moral imagination can create such a moral and personal stance, and the resultant coherent decision making processes can facilitate job accep tance, and rejection of the stigma.

\section{Managing dirty occupations imaginatively}

But how does moral imagination help dirty workers deal with conflicts by facilitating decision processes? Moral imagination shapes a personal moral attitude toward different moral conflicts, which activates personal moral decision making, and consequently shapes a particular stance toward the job itself. Specifically, moral imagination provides wider moral awareness and reveals workers' principles and values to themselves.

\section{Moral awareness in dirty conflicts}

Moral imagination has been proven to be a powerful mechanism in moral dilemmas and decision making that bestows creative moral awareness on ethical conflicts. In general, this faculty should provide greater awareness, creativity, and critical ability to make conscious, creative, and critical decisions. It recognizes the moral content and repercussions of a situation, which may not be evident. A broader consciousness and sharp creativity should be more relevant for work marked by moral and social con troversies, because these occupations require con scious decisions. The moral controversies that surround socially dirty work often hinder percep tions of the repercussions of decisions for the self, others involved, and the community in general. Because moral imagination activates deep sensitivity to the feelings and perceptions of others, it can 
evoke more potential and complete scenarios and perspectives. In general, moral imagination facilitates morally complex decision making by offering wider consciousness. Furthermore, the sorts of controver sies that emerge from dirty jobs are always complex but not always the same, so workers need creative, imaginative, and personal responses, which imagi nation can help provide.

The wider moral awareness provided by moral imagination on moral dilemmas also applies to the dirty worker's perception of the job. The exercise of moral imagination confers a better perception of the moral and social content of a job and its effects on the community. Moral imagination expands the perspective on the occupation and its repercussions for others and helps consolidate a personal position toward it. For jobs whose performance may provoke diverse interpretations, and constantly provokes ques tions about its social or moral repercussions among external groups, the effort to sharpen moral sensi tivity becomes even more relevant as a means to adopt an attitude that may come into conflict with others' positions. For example, people might view a bill collector as a villain or a defender of law; in either case, the bill collector must to be able to identify these diverse perceptions prompted by his or her occupation and the associated controversies, and then build a personal perception of the job and its performance. These cases demand creativity to determine the level of dignity associated with the work, which is not always easy. In particular, the person must be able to disengage him or herself from the dirt to visualize alternative views. Because these occupations are not conventional, moral imagination assists people in envisioning uncon ventional possibilities. Moral imagination also helps them disclose unconventional perceptions of their stigmatized job and discover their own perspective, coherent with their values.

\section{Values and principles}

One of the most relevant effects of moral imagina tion in dirty tasks is its ability to illuminate the worker's moral values and principles, which supports coherent decision making. In general, moral imag ination helps dirty workers solve conflicts in a way that is consistent with their values and hence build a coherent attitude toward their job. A personal moral attitude must be based on the person's own values and principles. Psychologists such as Festinger (1957) similarly argue that people desire coherence in their views, and Chaiken et al. (1996) assert that people want all their attitudes and beliefs to be coherent with their existing self definitional attitudes and beliefs. However, if people are not always conscious of their own values, recognizing them can be arduous (Hartman, 2006), especially in complex situations. Moral dilemmas and conflicts in the workplace offer the possibility to undertake this recognition task through the exercise of different faculties, including moral imagination.

Specifically, moral imagination illuminates core values and orients people toward decisions or posi tions that are coherent with those values (Lan et al., 2008). Thus, if a value that regulates a person's life is the rejection of the use of violence, that person should avoid jobs that likely require violence, such as law enforcement. However, the question goes beyond mere "fitting" or "feeling comfortable." That is, moral imagination discloses values, so people can make coherent decisions and build an ethical and personal attitude that contributes indirectly to overcoming external stigma. By facilitating coherent decision making processes, moral imagination might help the worker achieve a more positive perception of his or her work. In turn, the worker may feel more comfortable with a conflict laden dirty job, because its inherent moral conflicts can be addressed from the position of personal values and wide moral awareness, as provided by moral imagination. The positive perception of the job results from solving moral conflicts coherently with the person's own values.

In general, wider awareness and values disclosure, as conferred by moral imagination, should facilitate the solution of concrete moral dilemmas that arise during work and hence improve the worker's per ception of the job itself.

\section{Overcoming the stigma with others' moral imagination}

However, perceptions of stigma and its impact on self esteem do not affect only work groups. Exten sive literature in sociology, psychology, and psy chiatry identifies historical social stigmas and how subgroups overcame them, in some cases in the form 
of social movements. Members of society have suf fered social discrimination for a broad variety of reasons, including mental illnesses and disorders (Hinshaw, 2007; Kroska and Harkness, 2006), race (Loury, 2003), religion (Khazzoom, 2003), sexual preferences (Gentry, 1987), physical disabilities (Friedman, 2004), or specific behaviors (Stuber et al., 2008), to cite only a few. Gradually the per sons affected by different stigmas and their families form groups to combat, both individually and so cially, their societal rejection. To a certain extent, this progression also applies to our analysis; that is, the formal and informal association of workers who perform the same dirty work might offer a powerful resource to mitigate the negative effects of stigmas, both personally and for the group. Such groups might form spontaneously within the organization in which they work, but they usually emerge externally and connect dirty workers who perform similar tasks for different companies. There is thus a double effect of these congregations, at individual and collective levels.

The benefits of creating a group tend to be understood in terms of the benefits derived from group support. However, as an example of an association of dirty workers, the American Psychi atric Nurses Association serves to not only provide comfort to individual dirty workers - by identifying others with similar problems and sharing the expe rience of stigma - but also acknowledge and address the similar, morally complex situations that com plicate their daily tasks. Therefore, contacts with other members of the group might improve their moral imagination and facilitate their moral decision making. Through meetings with other members of the group, an individual dirty worker gains the opportunity to verbalize and share his or her experi ences and conflicts, then discover how other workers who have undergone similar moral conflicts in their work lives face them. In these empathic meetings, the individual moral imagination of a dirty worker likely improves, through listening and observing how oth ers have exercised their moral imagination in similar circumstances. The close association among the diverse dirty workers' moral imaginations should also improve workers' moral sensitivity and strengthen the moral abilities they need to address future ethical ambiguities. Moreover, for members of a dirty work group, the exchange of stories encourages them to disclose their own values and reflect on how they feel and think, such that they may define a clearer moral stance. Through this process, the worker refines his or her moral imagination by observing how other dirty workers exercise theirs. The resulting coherent decision making should generate relevant attitudinal changes at work. In addition, empathic encounters with other members of the same profession can help an individual worker discover dimensions and im pacts of his or her job that this person had previously ignored.

Work takes place in the context of a social structure that determines what evokes value. From an active social perspective, members can benefit from the strength of the group, because associations act as social pressure groups that demand, through the mediation of institutions, mitigation of the negative attitudes and low consideration of wider society. For example, dirty worker organizations might demand subsidies for their meetings, engage in campaigns to explain their contribution to society, and attempt to transmit the problems that their workers face. Such efforts and demands obviously have more effect if they come from a consolidated and organized group rather than from an individual.

\section{Managing moral imagination in organizations}

If the exercise of moral imagination in the workplace helps dirty workers face external stigma, it becomes crucial to understand how organizations that include dirty work groups can facilitate the exercise of their employees' moral imagination. How can organiza tions create a work space in which workers' moral imagination can flourish? This question is important not only for dirty work groups but also for compa nies, especially those that integrate both dirty and nondirty work groups, because problematic rela tionships or isolation of dirty workers can affect company performance.

In business ethics and psychology, several scholars have attempted to identify factors that induce people to engage in moral imagination (Caldwell and Moberg, 2006; Johnson, 1993; Vidaver Cohen, 1997). Our discussion centers not on the individual moral characteristics of decision makers (Aquino and Reed, 2002, 2003) but rather on the institutional 
factors and practices that encourage people's moral imagination. We therefore investigate how organi zations might create the conditions that inspire moral imagination by noting the importance of organizational culture for enhancing workers' moral sensitivity. Furthermore, in this section we analyze different company practices that may derive from a culture committed to moral imagination.

\section{Organizational cultures: ethics and community}

Extensive evidence in social research indicates that organizational culture has a powerful influence on people's behavior (O’Reilly et al., 1991; Treviño and Weaver, 2001), in that people tend to adapt to their culture's core values. Organizational cultures influence thoughts and feelings, as well as guide behaviors and decisions. We identify two elements often prioritized by organizational cultures aligned with members' moral imagination: ethics and com munity.

Significant evidence also reveals that organizations can support or oppose ethical behavior. Some studies note correlations between ethical organizational cultures and ethical individual behaviors (Treviño, 1986; Treviño et al., 1998), as well as an influence of corporate cultures on ethical decision making (Nwachukwu and Vitell, 1997). For example, Chen et al. (1997) argue that ethical behavior depends on employees' ability to recognize ethical issues, which is a function of corporate culture. Caldwell and Moberg (2006) similarly posit that organizations with an organizational culture that prioritizes ethics over other factors will be committed to enhancing their workers' moral imagination. Organizational cultures aligned with moral imagination do not attempt to promote a specific ethical value over another but instead encourage critical thinking by organizational members, inspired by their own values, to detect, understand, and prioritize ethical issues. This means that the company exhibits strong commitment to the particularity of the individual worker's values. Companies with dirty work groups should attempt to promulgate an organizational culture that is especially attentive to ethical themes and prioritize respect for critical thinking among workers. As we have explained, moral imagination acquires special relevance in such jobs.
Moberg and Seabright (2000) instead focus on a sense of community as a particular characteristic of moral imagination based cultures. Such organiza tional cultures strengthen community values and reinforce two fundamental aspects of moral imagi nation for dirty work groups: moral inclusion (Opotow, 1990) and the empathic processes involved in taking others' perspectives. Companies that include dirty work groups might try to avoid their isolation by promoting moral inclusion and encour aging perspective taking through direct contacts across their various work groups. By acquiring knowledge of others' perspectives, nonmarginalized groups and workers should grow to appreciate their feelings and concerns and recognize their contribu tion to the firm's global objectives. Direct contacts across work groups in the same company also may reveal the importance and contribution of the dirty work to the other functions. For example, a hospital might encourage doctors to realize the contribution of the cleaning staff to their ability to perform their jobs and to the efficient operations of the organization in general (Dutton et al., 1996). As we have noted, these empathic processes are more effective if undertaken through the exercise of moral imagina tion. By appreciating others' perspectives, a person should become more empathic toward stigmatized groups (Sheehan et al., 1989). Specifically, an imag inative assumption of the place of the dirty worker, who could be desperate for work or feeling displaced, questioned, or rejected, might mitigate the initial negative impression produced. Furthermore, being able to imagine what it is like to be stigmatized should lead the person to recognize the complexity of his or her situation. However, such empathy often requires nurturing of the capacity to imagine what it feels like to be a person marked by a social stigma. Organiza tions therefore might create means by which their members come into constant contact with dirty workers to encourage these empathic processes.

\section{Narratives}

Companies can use narratives as part of their culture to trigger the inclusive and empathic behaviors de scribed above. The use of narratives is coherent with an organizational culture attentive to community values and ethical themes. Meetings, narratives, and 
symbols provide symbolic practices that signify common roots and enhance the exercise of workers' moral imagination. The value of narratives in organizations has been explored previously (Coles, 1987, 1989; McAdams and Koppensteiner, 2004; McGregor and Holmes, 1999; Pardales, 2002). As these scholars show, the use of narratives generates greater awareness of the complexity of the person's own and others' moral conflicts, and activates deeper sensitivity to the feelings and perceptions of others. Narratives also broaden the intellectual space for a dialog among perspectives, players, and moral con flicts during ethical decision making processes or moral dilemmas. To establish a personal moral stance, people need both knowledge and imagina tion, as well as a recognition of the effects of their actions on others. Finally, people must be able to vividly imagine themselves in others' places. Narra tives offer a compelling method to achieve these requirements by improving workers' moral sensi tivity and strengthening the moral abilities they need to address ethical ambiguities. For members of a dirty work group, stories encourage them to think about what they want and believe, as well as to disclose their values. Moreover, imagination can provide the ability to construct positive symbolism and narratives that make dirty occupations more bearable. For those in contact with a dirty work group, narratives help enliven the empathic pro cesses.

\section{Job design}

In recent decades, research on job design has generated various insights into the factors that influ ence employees' responses to their jobs (Brosseau, 1985: Hackman and Oldman, 1980). We emphasize nonfragmentation and autonomy as two important variables that relate directly to the exercise of moral imagination. Because the design of a task determines its level of autonomy and responsibility, as well as its connection to tasks carried out by others, job design determines the possibility of exercising moral imagi nation in the workplace.

In a comparison of union and nonunion electri cians, for example, Murphy (1993) shows that occupational design might provide space for work ers' moral imagination - or not. Murphy particularly emphasizes the effects of the division of labor, which can limit the possibilities for exercising moral imagi nation in the workplace. Ruskin (2008) also cites the division of labor as a main cause of job unhappiness, and Bach et al. (2007) explain that shifts in the divi sion of labor can lead to empowerment or degrada tion in workplace roles. An extremely fragmented job seems monotonous and stifles the human capacity for thought and imagination. It also favors labor and social disconnection and leads to isolation and moral exclusion from other groups. In general, highly fragmented jobs do not allow for the exercise of moral imagination, because the worker cannot perceive his or her contribution and personal responsibility. Autonomy in carrying out a task, facing moral dilemmas, and making decisions is thus a prerequisite for the development of moral imagination in the workplace. The exercise of moral imagination also requires a job design that makes workers responsible for their outcomes and enables them to identify and evaluate their individual contributions to the collective.

In the specific case of dirty occupations, a lack of fragmentation and autonomy takes on even more relevance. The possibility of developing creative awareness becomes crucial, both to understand the dimensions and contributions of dirty work groups with which you interact and to be conscious of the relevance and involvement of one's own dirty occupation, in a more global context.

\section{Acknowledgments}

I would like to thank the editor of this journal and the anonymous reviewers and Prof. Mark Seabright for helpful and constructive comments. I acknowledge the financial support of the Spanish Ministry of Science and Innovation (ECO2009 08308) and the Fundación Ramón Areces. All the errors are author's responsibility.

\section{References}

Albert, S., B. Ashforth and J. Dutton: 2000, 'Organiza tional Identity and Identification: Charting New Waters and Building New Bridges', Academy Manage ment Review 25, 13. 
Alexander, T.: 1993, 'John Dewey and the Moral Imagination: Beyond Putman and Rorty Towards a Postmodern Ethics', Transactions of the Charles S. Pierce Society 29(2), 369-400.

Aquino, K. F. and A. Reed: 2002, 'The Self Importance of Moral Identity', Journal of Personality and Social Psy chology 83, 1432-1440.

Aquino, K. F. and A. Reed: 2003, 'Moral Identity and the Circle of Moral Regard Towards Out Groups', Journal of Personality and Social Psychology 84, 1270-1286.

Ashforth, B.: 2001, Role Transitions in Organizational Life: An Identity Based Perspective (Erlbaum, Mahwah, NJ).

Ashforth, B. and G. Kreiner: 1999, 'How can you do It? Dirty Work and the Challenge of Constructing a Positive Identity', Academy Management Review 24, 413-434.

Ashforth, B., G. Kreiner, M. Clark and M. Fugate: 2007, 'Normalizing Dirty Works: Managerial Tactics for Countering Occupational Taint', Academy Management Journal 50, 149-174.

Aviram, R. and M. Rosenfeld: 2002, 'Application of Social Identity Theory in Group Therapy with Stig matized Adults', International Journal of Group Psycho therapy 52, 121-130.

Bach, S., I. Kessler and P. Heron: 2007, 'The Conse quences of Assistant Roles in the Public Services: Degradation or Empowerment', Human Relations 60, 1267-1293.

Blasi, A. L.: 1980, 'Bridging Moral Cognition and Moral Action: A Critical Review of the Literature', Psycho logical Bulletin 88, 1-45.

Bolton, S.: 2005, 'Women's Work, Dirty Work: The Gynecology Nurse as 'Other', Gender, Work and Organization 12, 169-186.

Brosseau, K.: 1985, 'Towards a Dynamic Model of Job Person Relationships: Findings, Research Ques tions, and Implications for Work System Design', Academy Management Review 8, 33-45.

Caldwell, D. and D. Moberg: 2006, 'An Exploratory Investigation of the Effect of Ethical Culture in Acti vating Moral Imagination', Journal of Business Ethics 73, 193-204.

Chaiken, S., R. Giner Sorolla and S. Chen: 1996, 'Be yond Accuracy: Defense and Impression Motives in Heuristic and Systematic Information Processing', in P. M. Gollwitzer and J. A. Bargh (eds.), The Psychology of Action: Linking Cognition and Motivation to Behavior (Guilford, New York), pp. 553-578.

Chen, A., R. Sawyers and P. Williams: 1997, 'Rein forcing Ethical Decision Making Through Corporate Culture', Journal of Business Ethics 16, 855-865.

Coles, R.: 1987, 'Story Tellers' Ethics', Harvard Business Review 65, 8-14.
Coles, R.: 1989, The Call of Stories (Houghton Mills, Boston).

Collier, J.: 2006, 'The Art of Moral Imagination: Ethics in the Practice of Architecture', Journal of Business Ethics 66, 307-317.

Dick, P.: 2005, 'Dirty Work Designations: How Police Officers Account for Their Use of Coercive Force', Human Relations 58, 1363-1372.

Dutton, J., G. Debebe and A. Wrzesniewski: 1996, The Revaluing of Devalued Work: The Importance of Relationship for Hospital Clinic Staff. Paper Presented at the Annual Meeting of the Academy of Manage ment, Cincinnati, $\mathrm{OH}$.

Fesmier, S.: 1999, 'Morality as Art: Dewy, Metaphor and Moral Imagination', Transactions of the Charles S. Pierce Society 35, 527-550.

Festinger, L.: 1957, A Theory of Cognitive Dissonance (Stanford University Press, Stanford, CA).

Friedman, J.: 2004, 'Modern Science Versus the Stigma of Obesity', Nature Medicine 10, 563-569.

Gentry, C.: 1987, 'Social Distance Regarding Male and Female Homosexuals', Journal of Social Psychology 127, 199-208.

Goffman, E. L.: 1963, Stigma: Notes on the Management of Spoiled Identity (Simon \& Schuster, New York).

Hackman, J. R. and G. Oldman: 1980, Work Redesign (Addison Wesley, Reading, MA).

Hartman, E.: 2006, 'Can we Teach Character? An Aris totelian Answer', Academy of Management Learning and Education 5, 68-81.

Hartman, L., F. Wilson and D. Arnold: 2006, 'Positive Ethical Deviance Inspired by Moral Imagination: The Entrepreneur as Deviant', Journal for Business, Economics and Ethics 6, 343-358.

Hinshaw, S.: 2007, The Mark of Shame. Stigma of Mental Illness and an Agenda for Change (Oxford University Press, New York).

Hughes, E.: 1951, 'Work and the Self, in J. H. Rohrer and M. Sherif (eds.), Social Psychology at the Crossroads (Harper \& Brothers, New York), pp. 312-323.

Hughes, E.: 1962, 'Good People and Dirty Work', Social Problems 10, 3-11.

Jacobs, J.: 1991, 'Moral Imagination, Objectivity and Practical Wisdom', International Philosophical Quarterly 31, 23-37.

Johnson, M.: 1993, Moral Imagination (Chicago University Press, Chicago).

Kekes, J.: 1991, 'Moral Imagination, Freedom and the Humanities', American Philosophical Quarterly 28(2), 101-111.

Khazzoom, A.: 2003, 'The Great Chain of Orientalism: Jewish Identity, Stigma Management and Ethnic 
Exclusion in Israel', American Sociological Review 68, 481-510.

Kohlberg, L.: 1969, 'Stage and Sequence: The Cognitive Developmental Approach to Socialization', in D. A. Goslin (ed.), Handbook of Socialization Theory and Research (Rand McNally, Chicago, IL), pp. 347-480.

Kroska, A. and S. Harkness: 2006, 'Stigma, Sentiments and Self Meanings: Exploring the Modified Labeling Theory of Mental Illness', Social Psychology Quarterly 69, 325-348.

Lan, G., M. Gowing, S. McMahon, F. Rieger and N. King: 2008, 'A Study of the Relationship Between Personal Values and Moral Reasoning of Undergrad uate Business Students', Journal of Business Ethics 78, 121-139.

Larmore, C.: 1981, 'Moral Judgment', Review of Meta physics 35, 275-296.

Link, B. and J. L. Phelan: 2001, 'Conceptualizing Stig ma', Annual Review of Sociology 27, 363-385.

Loury, G.: 2003, 'Racial Stigma: Towards a New Para digm for Discrimination Theory', American Economic Review 93, 334-337.

Markus, H. and P. Nurius: 1986, 'Possible Selves', American Psychologist 41, 954-969.

McAdams, T. and R. Koppensteiner: 2004, 'The Managers Seeking Virtue: Lessons from Literature', Journal of Business Ethics 11, 627-634.

McCullough, T.: 1991, The Moral Imagination and Public Life: Raising the Ethical Question (Chatman House, NJ).

McGregor, I. and J. Holmes: 1999, 'How Storytelling Shapes Memory and Impressions of Relationship Events Over Time', Journal of Personality and Social Psychology 76, 403-419.

McKenna, B., D. Rooney and R. Ten Bos: 2007, 'Wisdom in Management', Social Epistemology 21(Special issue), 83-86.

Moberg, D. and M. Seabright: 2000, 'The Development of Moral Imagination', Business Ethics Quarterly 10, 845-884.

Murphy, J.: 1993, The Moral Economy of Labor. Aristotelian Themes in Economic Theory (Yale University Press, New Haven, CT).

Nussbaum, C.: 1990, Love's Knowledge: Essays on Philos ophy and Literature (Oxford University Press, New York).

Nwachukwu, S. and S. J. Vitell: 1997, 'The Influence of Corporate Culture on Managerial Ethical Judgments', Journal of Business Ethics 16, 757-776.

O'Reilly, C., J. Chatman and D. Caldwell: 1991, 'People and Organizational Culture: A Profile Comparison Approach to Assessing Person Organization Fit', Academy of Management Journal 34, 487-516.
Oermann, M. and S. Sperling: 1999, 'Stress and Chal lenge of Psychiatric Nursing Clinical Experiences', Archives of Psychiatric Nursing 13, 74-79.

Opotow, S.: 1990, 'Moral Exclusion and Injustice: An Introduction', Journal of Social Issues 46, 1-20.

Paetzold, R., R. Dipboye and K. Elsbach: 2008, 'A New Look at Stigmatization in and of Organizations', Academy of Management Review 33, 186-193.

Pardales, M. J.: 2002, 'So how did you Arrive at that Decision? Connecting Moral Imagination and Moral Judgment', Journal of Moral Education 31, 423-437.

Piaget, J.: 1932, The Moral Development of the Child (Kegan, Paul, London).

Pratt, M.: 1998, 'To be or not to be? Central Questions in Organizational Identification', in D. A. Whetten and P. C. Godfrey (eds.), Identity in Organizations: Building Theory Through Conversations (Sage, Thousand Oaks, CA), pp. 171-207.

Roca, E.: 2007, 'Intuitive Practical Wisdom in Organi zational Life', Social Epistemology 21, 195-207.

Roca, E.: 2008, 'Introducing Practical Wisdom in Busi ness Schools', Journal of Business Ethics 82, 607-620.

Ruskin, J.: 2008, Stones of Venice (Da Capo, New York).

Schwalbe, M.: 1991, 'Role Taking, Self Monitoring, and the Alignment of Conduct with Others', Personality and Social Psychology Bulletin 17, 51-57.

Seabright, M. and J. Schminke: 2002, 'Immoral Imagi nation and Revenge in Organizations', Journal of Business Ethics 38, 19-31.

Sheehan, E., R. Lennon and T. Mc Dermitt: 1989, 'Reactions to AIDS and Other Illnesses: Reported Interactions in the Workplace', Journal of Psychology 123, 525-536.

Stuber, J., S. Galea and B. Link: 2008, 'Smoking and the Emergence of Stigmatized Social Status', Social Science and Medicine 67, 420-430.

Tivnan, E.: 1995, The Moral Imagination (Simon \& Schuster, New York).

Tracy, S.: 2004, 'The Construction of Correctional Officers: Layers of Emotionality Behind Bars', Quali tative Inquiry 10, 509-533.

Treiman, D.: 1977, Occupational Prestige in Comparative Perspective (Academic, New York).

Treviño, L.: 1986, 'Ethical Decision Making in Organi zations: A Person Situation Interactionist Model', Academy of Management Review 11, 601-617.

Treviño, L., K. Butterfield and D. McCabe: 1998, 'The Ethical Context on Organizations: Influences on Employee Attitudes and Behaviors', Business Ethics Quarterly 8, 447-476.

Treviño, L. and G. Weaver: 2001, 'Organizational Justice and Ethics Program 'Follow Through': Influences on 
Employees' Harmful and Helpful Behavior', Business Ethics Quarterly 11, 651-669.

Vidaver Cohen, D.: 1997, 'Moral Imagination in Orga nizational Problem Solving: An Institutional Perspec tive', Business Ethics Quarterly 7, 1-26.

Wells, J. S., D. Ryan and C. N. McElwee: 2000, “'I don't Want to be a Psychiatric Nurse": An Exploration of Factors Inhibiting Recruitment to Psychiatric Nursing in Ireland', Journal of Psychiatric and Mental Health Nursing 7, 79-87.

Werhane, P. H.: 1998, 'Moral Imagination and the Search for Ethical Decision Making in Management', Business Ethics Quarterly, Special issue 1, 75-98.
Werhane, P. H.: 1999, Moral Imagination and Management Decision Making (Oxford University Press, New York). Williams, O.: 1997, The Moral Imagination: How Literature and Films can Stimulate Ethical Reflection in the Business World (University of Notre Dame Press, Notre Dame, IN).

Universidad Carlos III Madrid, Madrid, Spain E-mail: esther.roca@uc3m.es 